\title{
Phase Transformations in Pyrochlores Irradiated with Swift Heavy Ions: Influence of Composition and Chemical Bonding
}

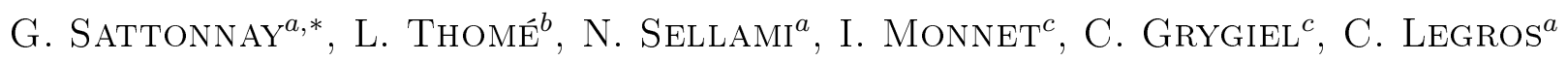 \\ AND R. TETOT ${ }^{a}$ \\ ${ }^{a}$ Univ. Paris Sud, ICMMO-LEMHE, Bât. 410, F-91405 Orsay, France \\ ${ }^{b}$ CSNSM, CNRS, IN2P3, Université Paris-Sud, Bât. 108, F-91405 Orsay, France \\ ${ }^{c}$ CIMAP, CEA, CNRS, Université de Caen, BP 5133, F-14070 Caen Cedex 5, France
}

\begin{abstract}
$\mathrm{Gd}_{2} \mathrm{Ti}_{2} \mathrm{O}_{7}$ and $\mathrm{Gd}_{2} \mathrm{Zr}_{2} \mathrm{O}_{7}$ pyrochlores were irradiated with swift heavy ions in order to investigate the effects of the chemical composition on the structural changes induced by high electronic excitation. The XRD results show that the structural modifications induced by irradiation with $93 \mathrm{MeV}$ Xe ions are strongly dependent on the sample composition: $\mathrm{Gd}_{2} \mathrm{Ti}_{2} \mathrm{O}_{7}$ is readily amorphized, whereas $\mathrm{Gd}_{2} \mathrm{Zr}_{2} \mathrm{O}_{7}$ is transformed into a radiation-resistant anion-deficient fluorite structure. Atomistic simulations with the second-moment tight-binding QEq model allow us to calculate the lattice properties of both $\mathrm{Gd}_{2} \mathrm{Ti}_{2} \mathrm{O}_{7}$ and $\mathrm{Gd}_{2} \mathrm{Zr}_{2} \mathrm{O}_{7}$, and also to quantify the degree of covalency and ionicity in these compounds. These calculations clearly show that $\mathrm{Gd}_{2} \mathrm{Ti}_{2} \mathrm{O}_{7}$ is more covalent than $\mathrm{Gd}_{2} \mathrm{Zr}_{2} \mathrm{O}_{7}$, thus confirming that the amorphization resistance can be related to the covalent character of insulators.
\end{abstract}

DOI: $10.12693 /$ APhysPolA.123.862

PACS: 61.80.-x, 61.82.Ms, 61.05.cp, 05.10.-a

\section{Introduction}

Pyrochlores with the $\mathrm{A}_{2} \mathrm{~B}_{2} \mathrm{O}_{7}$ stoichiometry provide a large array of structural and physical properties related to their various chemical compositions. In particular, due to the capability to incorporate actinides (e.g. U, Np, Th, $\mathrm{Pu}, \mathrm{Am}$ and $\mathrm{Cm}$ ), the $\mathrm{A}_{2}^{3+} \mathrm{B}_{2}^{4+} \mathrm{O}_{7}$ series is of great interest in the field of nuclear waste management [1]. Ordered $\mathrm{A}_{2} \mathrm{~B}_{2} \mathrm{O}_{7}$ pyrochlores belong to the $F d \overline{3} \mathrm{~m}$ space group which is a superstructure of the ideal fluorite structure ( $F m \overline{3} m$ space group) with twice as large the lattice constant. A and B cations occupy the $16 \mathrm{c}(0,0,0)$ and $16 \mathrm{~d}$ $(0.5,0.5,0.5)$ sites, respectively, and oxygens are located at the $48 \mathrm{f}(x, 0.125,0.125)$ and $8 \mathrm{~b}(0.375,0.375,0.375)$ positions (using the Wyckoff notation). The anion sublattice can be completed by adding missing oxygens in the $8 \mathrm{a}$ site to form the fluorite structure. The stability of the pyrochlore structure is governed by the ratio of the ionic radii of $\mathrm{A}$ and $\mathrm{B}$ cations $\left(r_{\mathrm{A}} / r_{\mathrm{B}}\right)$ which extends from 1.46 for $\mathrm{Gd}_{2} \mathrm{Zr}_{2} \mathrm{O}_{7}$ to 1.78 for $\mathrm{Sm}_{2} \mathrm{Ti}_{2} \mathrm{O}_{7}$ [1, 2].

Recently, due to the high radiation resistance of some compositions, with an amorphization tolerance comparable to fluorite zirconia [3-6], pyrochlores were considered as potential matrices for the immobilization or transmutation of actinides produced in nuclear power plants [1]. Although the crystalline-to-amorphous phase transformation induced by low-energy ion irradiation in pyrochlores drew much attention in the past [1, 7-14], information concerning the damage due to electronic excitation arising from irradiation with swift ions (hun-

*corresponding author; e-mail: gael.sattonnay@u-psud.fr dred $\mathrm{MeV}$ range) is still incomplete owing to the small number of experiments devoted to this topic [15-22]. One of the main results is that the susceptibility to radiation-induced amorphization exhibits a systematic decrease with the increasing $\mathrm{Zr}$ content, as it has also been observed for irradiations performed with low-energy ions. Whereas $\mathrm{Gd}_{2} \mathrm{Ti}_{2} \mathrm{O}_{7}$ is readily amorphized, the end member $\mathrm{Gd}_{2} \mathrm{Zr}_{2} \mathrm{O}_{7}$ is transformed into a radiation resistant anion-deficient fluorite structure upon irradiation at room temperature [10-13, 16-22]. From these results, it was concluded that zirconates are more radiation resistant than titanates, and ion-beam induced amorphization increased with the increasing B-site cation size from $\mathrm{Gd}_{2} \mathrm{Ti}_{2} \mathrm{O}_{7}$ to $\mathrm{Gd}_{2} \mathrm{Zr}_{2} \mathrm{O}_{7}$. Nevertheless, recent studies showed that some zirconates $\left(\mathrm{Nd}_{2} \mathrm{Zr}_{2} \mathrm{O}_{7}, \mathrm{Sm}_{2} \mathrm{Zr}_{2} \mathrm{O}_{7}\right.$, and $\left.\mathrm{Eu}_{2} \mathrm{Zr}_{2} \mathrm{O}_{7}\right)$ can be amorphized by high electronic excitations $[19,22]$. Moreover, it is now believed that the radiation response cannot be described exclusively in terms of the cationic radius ratio: the defect-formation energies and the bond type (i.e. the electronic structure of compounds) must be considered $[1,11,23]$. It has been suggested that the resistance of materials to amorphization in a complex non-metallic compound is determined by a competition between short-range covalent interactions and long-range ionic forces. However, it is not easy to quantify the covalency and ionicity and to relate these parameters to the radiation resistance.

This paper reports a comparative study of the damage created by swift heavy ions in $\mathrm{Gd}_{2} \mathrm{Ti}_{2} \mathrm{O}_{7}$ and $\mathrm{Gd}_{2} \mathrm{Zr}_{2} \mathrm{O}_{7}$ in order to investigate the effects of the chemical composition on the radiation resistance. X-ray diffraction (XRD) was implemented to determine the structural changes induced by irradiation, as well as to monitor the damage build-up. Moreover, in an attempt to ex- 
plain some experimental observations concerning the radiation resistance of pyrochlores as a function of their composition, numerical calculations were performed using a new variable-charge model (the so-called SMTB-Q model, second-moment tight-binding-QEq) [24, 25]. This model takes advantage of an oxygen-metal interatomic potential which better describes the iono-covalent bonding of oxides than the classical purely ionic potentials. It was used in the present work to determine the role played by the ionicity of the metal-oxygen bond on the radiation tolerance. Moreover, the fact that all pyrochlores have the same structure makes them an excellent playground to test the relevance of the role of the bond type.

\section{Experimental results}

\subsection{Experimental}

Polycrystalline pyrochlore pellets were prepared by a standard solid state process. Stoichiometric amounts of $\mathrm{A}_{2} \mathrm{O}_{3}$ and $\mathrm{BO}_{2}$ oxides were intimately mixed in an acetone slurry using a ball-mill and subsequently dried. After drying, the powders were isostatically pressed into rods at $250 \mathrm{MPa}$. The homogenized mixtures were then subjected to a three step heating protocol with intermittent grindings to attain a better homogeneity. The compacts were first sintered at $1200^{\circ} \mathrm{C}$ for $12 \mathrm{~h}$. The procedures (grinding, milling, pressing) were repeated twice with the second heating at $1400{ }^{\circ} \mathrm{C}$ for $72 \mathrm{~h}$ and the final sintering in air at $1450^{\circ} \mathrm{C}$ for $196 \mathrm{~h}$ in order to increase the density of samples. Pellets were cut with a diamond saw and the specimens were polished to a $0.5 \mu \mathrm{m}$ diamond finish. Some properties of the investigated pyrochlores are listed in Table I which indicates that they strongly depend on the cation radius ratio $\left(r_{\mathrm{A}} / r_{\mathrm{B}}\right)$.

TABLE I

Cross-sections extracted from the fits to XRD experimental data with Eq. (1) (see text) for the different compounds. $\sigma_{\mathrm{PA}}$ and $\sigma_{\mathrm{PF}}$ hold for the amorphous-pyrochlore and fluorite-pyrochlore phase transformations, respectively. Comparison of the track diameters $(d)$ determined by XRD is also reported.

\begin{tabular}{c|c|c}
\hline \hline Compound & $\mathrm{Gd}_{2} \mathrm{Zr}_{2} \mathrm{O}_{7}$ & $\mathrm{Gd}_{2} \mathrm{Ti}_{2} \mathrm{O}_{7}$ \\
\hline$r_{\mathrm{A}} / r_{\mathrm{B}}$ & 1.46 & 1.72 \\
$\sigma_{\mathrm{PA}}\left[\mathrm{nm}^{2}\right]$ & 0 & $106 \pm 7$ \\
$\sigma_{\mathrm{PF}}\left[\mathrm{nm}^{2}\right]$ & $47 \pm 2$ & 0 \\
$d[\mathrm{~nm}]$ & $7.5 \pm 0.5$ & $11.6 \pm 0.5$
\end{tabular}

Pyrochlore oxides were irradiated at room temperature with $93 \mathrm{MeV}$ Xe ions at the GANIL accelerator in Caen at the fluences ranging from $2.5 \times 10^{11}$ up to $10^{14} \mathrm{~cm}^{-2}$. The ion current was always kept lower than $10^{8} \mathrm{~cm}^{-2} \mathrm{~s}^{-1}$ in order to maintain target temperature less than $50^{\circ} \mathrm{C}$. SRIM 2008 calculations [26] indicate that the projected range of $\mathrm{U}$ ions $R_{\mathrm{p}} \approx 8.3 \mu \mathrm{m}$, the electronic stopping power $S_{\mathrm{e}} \approx 20 \mathrm{keV} / \mathrm{nm}$ and the nuclear stopping power $S_{\mathrm{n}} \approx 0.3 \mathrm{keV} / \mathrm{nm}$ (in the depth range investigated by XRD); these values depend slightly on the sample composition. Thus, in the present experiments $S_{\mathrm{e}}$ exceeds $S_{\mathrm{n}}$ by several orders of magnitude.
XRD experiments were performed with a X'pert Pro MRD PANalytical diffractometer, using the $\mathrm{Cu} K_{\alpha}$ anticathode $\left(\lambda_{K \alpha 1}=0.1540598 \mathrm{~nm}, \lambda_{K \alpha 2}=0.1544426 \mathrm{~nm}\right)$. $\mathrm{X}$-ray patterns were recorded in a standard $(\theta-2 \theta)$ geometry in the $13^{\circ}-90^{\circ}$ range $(2 \theta)$ with a step of $0.025^{\circ}$. The penetration depth of X-rays in the investigated pyrochlores is $\approx 1.7 \mu \mathrm{m}$.

\subsection{XRD results and phase transformation build-ups}

Figure 1 shows the XRD patterns recorded on $\mathrm{Gd}_{2} \mathrm{Ti}_{2} \mathrm{O}_{7}$ and $\mathrm{Gd}_{2} \mathrm{Zr}_{2} \mathrm{O}_{7}$ irradiated with $93 \mathrm{MeV} \mathrm{Xe}$ ions. For $\mathrm{Gd}_{2} \mathrm{Ti}_{2} \mathrm{O}_{7}$ progressive vanishing of all diffraction peaks is observed and the additional diffuse scattering occurs at the basis of the (222) pyrochlore peak. These features indicate the amorphization of samples, which is totally achieved at $5 \times 10^{12} \mathrm{~cm}^{-2}$. Conversely, for $\mathrm{Gd}_{2} \mathrm{Zr}_{2} \mathrm{O}_{7}$ the diffraction peaks related to the supercell of the pyrochlore structure disappear and only the peaks corresponding to the fluorite structure are observed at $5 \times 10^{12} \mathrm{~cm}^{-2}$. This result indicates that irradiation has induced an order-disorder phase transition: zirconates are transformed into the anion-deficient fluorite structure by the disordering of cations occupying the $\mathrm{A}$ and $\mathrm{B}$ sites.

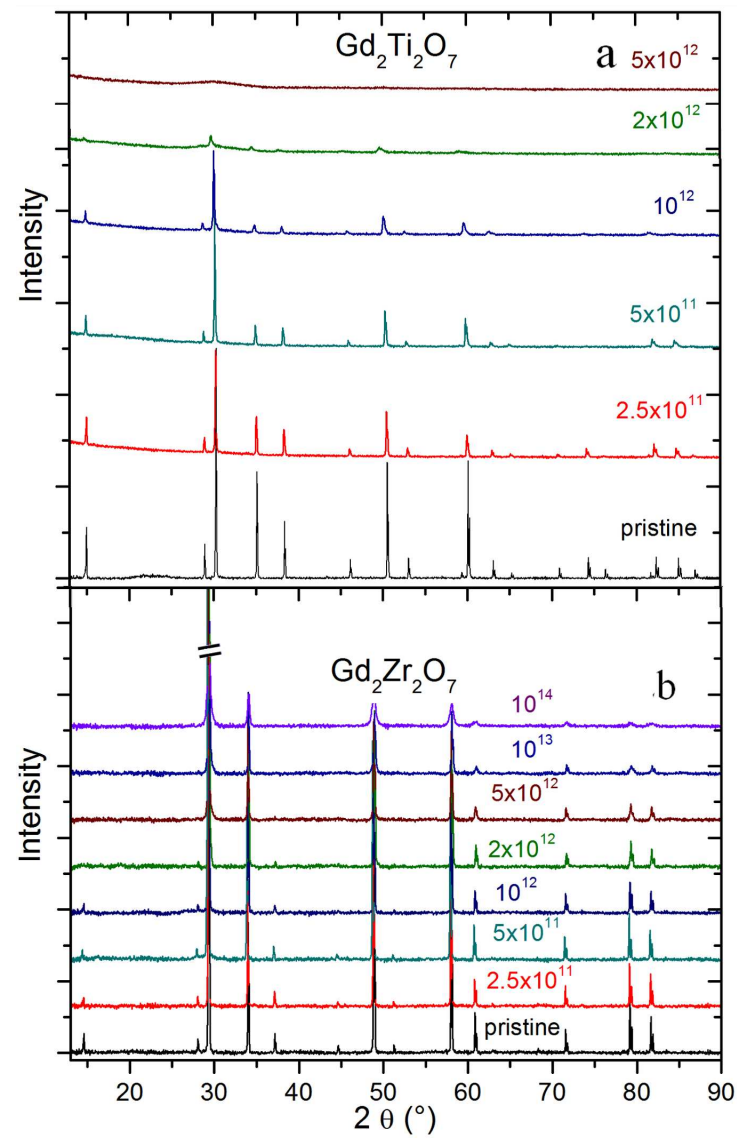

Fig. 1. XRD patterns recorded on $\mathrm{Gd}_{2} \mathrm{Ti}_{2} \mathrm{O}_{7}$ (a) and $\mathrm{Gd}_{2} \mathrm{Zr}_{2} \mathrm{O}_{7}$ (b) pellets before and after irradiation at increasing fluences with $93 \mathrm{MeV}$ Xe ions. 


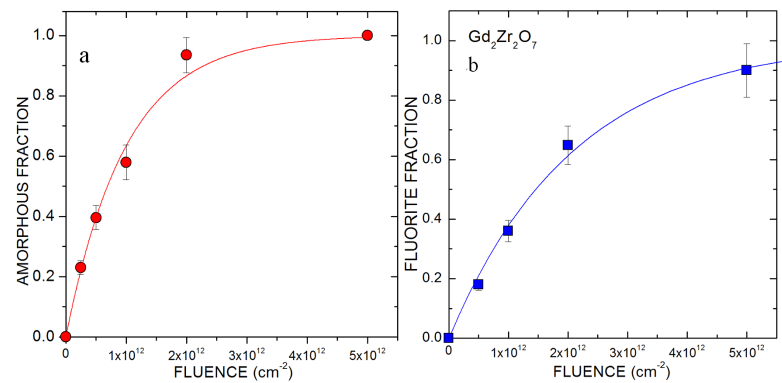

Fig. 2. Variation of the fraction of amorphous or fluorite phases versus the ion fluence for $\mathrm{Gd}_{2} \mathrm{Ti}_{2} \mathrm{O}_{7}$ (a) and $\mathrm{Gd}_{2} \mathrm{Zr}_{2} \mathrm{O}_{7}$ (b) irradiated with $93 \mathrm{MeV}$ Xe. Lines are fits to XRD data with Eq. (1).

Amorphous, anion-deficient fluorite and remaining pyrochlore phase fractions were determined from the analysis of XRD data (see the methodology used in Ref. [19]). Figure 2 compares the phase transformation build-ups, i.e. the variation versus the ion fluence of the fraction of a new phase (either amorphous or fluorite), obtained for $\mathrm{Gd}_{2} \mathrm{Ti}_{2} \mathrm{O}_{7}$ and $\mathrm{Gd}_{2} \mathrm{Zr}_{2} \mathrm{O}_{7}$. These build-ups were extracted from the analysis of XRD data according to the procedure described previously. The results show that only the pyrochlore $(\mathrm{P}) \rightarrow$ amorphous $(\mathrm{A})$ transformation is observed for $\mathrm{Gd}_{2} \mathrm{Ti}_{2} \mathrm{O}_{7}$. On the other hand, only the pyrochlore $(\mathrm{P}) \rightarrow$ anion-deficient fluorite $(\mathrm{F})$ transition occurs in $\mathrm{Gd}_{2} \mathrm{Zr}_{2} \mathrm{O}_{7}$.

\subsection{Analysis of phase transformation build-ups}

It is now well established that the electronic excitation resulting from the slowing-down of swift ions in insulating materials leads to the creation of cylindrical damaged regions, referred to as ion tracks. Phase transformation build-ups similar to those exhibited in Fig. 2 are thus generally accounted for in the framework of a single impact model [27]. In this model, it is assumed that total phase transformation is produced by the ion impinging into an undamaged region (only one impact is generally sufficient to totally transform the matter inside the ion track), the overall damage observed at high fluence results from the overlapping of a large number of ion tracks. Thus, the variation of the transformed fraction, $f$, with the ion $\mathrm{flu}$ ence follows the simple equation:

$$
f=f_{\text {sat }}[1-\exp (-\sigma \phi)]
$$

where $f_{\text {sat }}$ is the transformed fraction at saturation (i.e. at very high fluence), $\sigma$ is the section of the cylinder surrounding the ion path in which the transformation occurred, and $\phi$ is the ion fluence. If the pyrochlore-amorphous phase transformation is observed, the related cross-section is $\sigma_{\mathrm{PA}}$, whereas for a pyrochlore-defect fluorite phase transformation the cross-section is $\sigma_{\mathrm{PF}}$.

The phase transformation build-ups obtained for the ion irradiations performed in this work are fitted with Eq. (1) (see solid lines in Fig. 2). The cross-sections $\sigma_{i}$ extracted from the fits to the XRD data are given in Table II.
TABLE II

Lattice parameter $(a)$, 48f oxygen parameter $(x)$, bulk modulus $(B)$ and cohesive energy $\left(E_{\mathrm{coh}}\right)$ calculated with the SMTB-Q model for $\mathrm{Gd}_{2} \mathrm{Ti}_{2} \mathrm{O}_{7}$ and $\mathrm{Gd}_{2} \mathrm{Zr}_{2} \mathrm{O}_{7}$, and comparison to experimental values.

\begin{tabular}{c|c|c|c|c}
\hline & \multicolumn{2}{|c|}{$\mathrm{Gd}_{2} \mathrm{Ti}_{2} \mathrm{O}_{7}$} & \multicolumn{2}{c}{$\mathrm{Gd}_{2} \mathrm{Zr}_{2} \mathrm{O}_{7}$} \\
\hline & Calculated & Experimental & Calculated & Experimental \\
\hline$a[\AA]$ & 10.1843 & $10.1850[2]$ & 10.5348 & $10.5350[2]$ \\
\hline$x_{48 \mathrm{f}}$ & 0.338 & $0.326[2]$ & 0.348 & $0.343[2]$ \\
\hline$B[\mathrm{GPa}]$ & 184 & $186[28]$ & 164 & $169[28]$ \\
\hline$E_{\text {coh }[\mathrm{eV}]}$ & -74.9 & $-75^{*}$ & -82.7 & $-80.7^{*}$ \\
\hline${ }^{*}$ Estimated from thermodynamical data.
\end{tabular}

The results show that the tracks created in the wake of swift ions are entirely fluorite in $\mathrm{Gd}_{2} \mathrm{Zr}_{2} \mathrm{O}_{7}$, and are mostly amorphous in $\mathrm{Gd}_{2} \mathrm{Ti}_{2} \mathrm{O}_{7}$. The structures of these tracks have been recently confirmed by the TEM experiments on pyrochlores irradiated with $120 \mathrm{MeV} \mathrm{U}$ ions [22]: either an amorphous core (e.g. in $\mathrm{Gd}_{2} \mathrm{Ti}_{2} \mathrm{O}_{7}$ ) surrounded by the anion-deficient fluorite shell (e.g. in $\mathrm{Gd}_{2} \mathrm{TiZrO}_{7}$ ) or the entirely fluorite core (e.g. in $\mathrm{Gd}_{2} \mathrm{Zr}_{2} \mathrm{O}_{7}$ ) were observed.

The diameter of ion tracks $(d)$ may be deduced from the value found for $\sigma_{i}$ according to the equation

$$
d=2\left(\sigma_{i} / \pi\right)^{1 / 2} \text {. }
$$

The values of $d$ extracted from the fits to the XRD data are reported in Table I. The results show that the track diameter increases with $r_{\mathrm{A}} / r_{\mathrm{B}}$ and are slightly smaller than those observed upon irradiation with $120 \mathrm{MeV} \mathrm{U}$ ions [22] for which the electronic energy loss is higher $(25 \mathrm{keV} / \mathrm{nm})$.

\section{Atomistic simulation results}

\subsection{Brief description of the $S M T B-Q$ model}

The SMTB-Q (for second-moment tight-binding QEq) model is a new transferable variable-charge model aimed at describing the stability, structure and defects formed in the bulk and at oxide surfaces [24, 25, 29]. This model allows one to vary ion charges and to take into account both the ionic and covalent character of bonds [24, 25]. Thus, a more realistic description of the chemical bonding is achieved, in contrast to the previous works using pure ionic models (see e.g. in [30]), so that more realistic values of the energies of defect formation can be obtained. Such a model was successfully applied to $\mathrm{TiO}_{2}$ to describe bulk properties and to calculate both the formation energy of oxygen vacancies and the surface energies [24, 25]. In this model, the first original hypothesis is that the Coulomb interactions between ions (cation-oxygen) are described by the Qeq model [31] in which the electrostatic contribution is reduced with respect to the formal charge models, firstly by the reduction of ionic charges and secondly by the shielding between charges.

The second original hypothesis is that the metaloxygen covalent bonding energy is calculated thanks to the tight-binding analytical description [32]: $E_{\text {cov }}=$ $-\xi \sqrt{Z_{\mathrm{O}}} \sqrt{\left(2-\left|Q_{\mathrm{O}}\right|\right)\left(2 n_{0} / m-\left(2-\left|Q_{\mathrm{O}}\right|\right)\right)}$. In this equation, $\xi$ is the hopping integral between oxygen $2 p$ and 
outer metal orbitals, $Z_{\mathrm{O}}, Q_{\mathrm{O}}$ and $m$ are the coordination number, the charge and the stoichiometry of oxygen respectively, $n_{0}$ is the number of coupled electronic states between oxygen and metal sublattices. Actually $E_{\text {cov }}$ is as a function of $\xi \sqrt{Z_{\mathrm{O}}}$ (as in metals [32]) and of the oxygen-cation electron transfer: $\delta Q=2-\left|Q_{\mathrm{O}}\right|$. In the classical ionic models, $E_{\mathrm{cov}}=0\left(\left|Q_{\mathrm{O}}\right|=2\right)$ and the cohesive energy is purely electrostatic, this latter property failing account for the iono-covalent character of the metal-oxygen bond in oxides. Therefore, a new model of interatomic potential was derived to describe the metaloxygen (M-O) chemical bonding. The interaction energy of an atom with its neighbours is thus given by

$$
\begin{aligned}
E_{i} & =\sum_{j, R_{i j}<R_{\mathrm{C}}} A \exp \left(-p\left(\frac{R_{i j}}{R^{0}}-1\right)\right) \\
& -\sqrt{\sum_{j, R_{i j}<R_{\mathrm{C}}} \xi \exp \left(-2 q\left(\frac{R_{i j}}{R^{0}}-1\right)\right) \Delta Q_{\mathrm{O}_{\mathrm{ij}}},}
\end{aligned}
$$

where $A, p, \xi$, and $q$ are the adjustable parameters, $R^{0}$ is the first neighbour $\mathrm{M}-\mathrm{O}$ distance and $R_{\mathrm{C}}$ is the cut-off radius. Apart from the dependence on ionic charges, this interatomic potential is clearly close to that developed in the second moment approximation of the tight binding (TB-SMA) scheme for transition metals [33]. For the other short range interactions, the cation-cation ones can be neglected, and the oxygen-oxygen interactions are described by the Buckingham potential. The detailed description of the SMTB-Q model can be found in $[24,25]$. All the calculations were performed using the Monte Carlo code SMASH [34].

In this model, the loss of electrostatic energy is balanced by the gain in the energy associated with the short-range interactions, which are not purely repulsive as in the classical ionic models, but have an attractive part corresponding to the covalent part of the metal-oxygen bond. Furthermore, atomistic simulations using empirical interatomic potentials allow performing calculations on a great number of atoms (up to millions) at finite temperature, a task which is not yet conceivable by means of $a b$ initio techniques, and the description of the chemical bonding obtained with such potentials is incomparably faster than that using first principles, even if this latter is more reliable. Additionally, the density functional theory (DFT) approach for the first principle calculations applied to atoms with localized orbitals such as $4 f$ electrons (as in $\mathrm{Gd}_{2} \mathrm{Zr}_{2} \mathrm{O}_{7}$ for instance) is not straightforward, leading in some cases to prediction of a metallic-type conduction whereas the compound is an insulator, and thus fails to predict the correct electronic structure of compounds containing rare earths. The SMTB-Q model is thus used for the first time in the present work to calculate properties in pyrochlores.

\subsection{Results}

The adjustable parameters of the model were optimized to reproduce the bulk properties of $\mathrm{Gd}_{2} \mathrm{Ti}_{2} \mathrm{O}_{7}$ and
$\mathrm{Gd}_{2} \mathrm{Zr}_{2} \mathrm{O}_{7}$ : lattice parameters, cohesive energy and bulk modulus. An excellent agreement is obtained between the calculated and experimental values (see Table II). The electronic charges of ions $\left(\mathrm{Gd}, \mathrm{Ti}, \mathrm{Zr}, \mathrm{O}_{48 \mathrm{f}}\right.$ and $\mathrm{O}_{8 \mathrm{~b}}$ ) and the charge transfers were also calculated in both $\mathrm{Gd}_{2} \mathrm{Ti}_{2} \mathrm{O}_{7}$ and $\mathrm{Gd}_{2} \mathrm{Zr}_{2} \mathrm{O}_{7}$ compounds. The results are reported in Table III. The charge transfer $\left(\delta Q_{\text {cation }}\right)$ due to the covalent effects represents the difference between the formal charge (purely ionic case) of the cation and its calculated charge with the model, for each cation-oxygen bond. It is thus an indication of the ionicity/covalency of the cation-oxygen bond: the higher $\delta Q_{\text {cation }}$, the higher covalency. It appears clearly that the $\langle\mathrm{Gd}-\mathrm{O}\rangle$ bond has the same ionicity in $\mathrm{Gd}_{2} \mathrm{Ti}_{2} \mathrm{O}_{7}$ and $\mathrm{Gd}_{2} \mathrm{Zr}_{2} \mathrm{O}_{7}$, whereas a significant difference between the $\langle\mathrm{Ti}-\mathrm{O}\rangle$ and $\langle\mathrm{Zr}-\mathrm{O}\rangle$ bonds is observed: $\langle\mathrm{Ti}-\mathrm{O}\rangle$ is significantly more covalent than $\langle\mathrm{Zr}-\mathrm{O}\rangle$. Several works suggested that the bond type should be taken into account to explain the radiation behaviour of pyrochlores [23, 35]. Naguib and Kelly correlated the radiation tolerance of non-metallic solids with the relative ionicity of the materials, demonstrating that more covalently bonded materials are more readily amorphized under heavy ion irradiation [35]. Consequently, as it was experimentally observed that $\mathrm{Gd}_{2} \mathrm{Zr}_{2} \mathrm{O}_{7}$ is more resistant to amorphization than $\mathrm{Gd}_{2} \mathrm{Ti}_{2} \mathrm{O}_{7}$, we confirm that the radiation tolerance of non-metallic compounds can be related to the covalent character of the metaloxygen bond.

TABLE III

Calculated electronic charge $(|e|)$ and charge transfer $\delta Q_{\text {Cation }}$ for $\mathrm{Gd}_{2} \mathrm{Ti}_{2} \mathrm{O}_{7}$ and $\mathrm{Gd}_{2} \mathrm{Zr}_{2} \mathrm{O}_{7} . \delta Q_{\text {Cation }}=$ $\left(Q_{\text {Cation }}^{\text {Formal }}-Q_{\text {Cation }}^{\text {Calculat }}\right) / Z_{\mathrm{C}}$, where $Q_{\text {Cation }}^{\text {Formal }}$ is the formal charge of cation ( +4 for B-type cation and +3 for $\mathrm{Gd})$, $Q_{\text {Cation }}^{\text {Calculated }}$ is the calculated charge and $Z_{\mathrm{C}}$ is the total oxygen coordination of a cation ( 8 for Gd, 6 for B-type cation).

\begin{tabular}{c|c|c}
\hline \hline & $\mathrm{Gd}_{2} \mathrm{Ti}_{2} \mathrm{O}_{7}$ & $\mathrm{Gd}_{2} \mathrm{Zr}_{2} \mathrm{O}_{7}$ \\
\hline $\mathrm{Gd}$ & 2.02 & 1.98 \\
$\mathrm{~B}(\mathrm{Ti}$ or $\mathrm{Zr})$ & 1.70 & 1.97 \\
$\mathrm{O}_{48 \mathrm{f}}$ & -1.08 & -1.17 \\
$\mathrm{O}_{8 \mathrm{~b}}$ & -0.93 & -0.87 \\
$\delta Q_{\mathrm{Gd}}$ & 0.123 & 0.128 \\
$\delta Q_{\mathrm{B}(\mathrm{Ti} \text { or } \mathrm{Zr})}$ & 0.383 & 0.172
\end{tabular}

\section{Conclusion}

$\mathrm{Gd}_{2} \mathrm{Ti}_{2} \mathrm{O}_{7}$ and $\mathrm{Gd}_{2} \mathrm{Zr}_{2} \mathrm{O}_{7}$ pyrochlores were irradiated with $93 \mathrm{MeV}$ Xe ions in order to investigate the structural modifications induced by electronic excitation in these materials. X-ray diffraction data show that these structural modifications are strongly dependent on the sample composition: $\mathrm{Gd}_{2} \mathrm{Ti}_{2} \mathrm{O}_{7}$ is readily amorphized, whereas $\mathrm{Gd}_{2} \mathrm{Zr}_{2} \mathrm{O}_{7}$ is transformed into a radiation-resistant anion-deficient fluorite structure.

Atomistic calculations with the SMTB-Q model concerning both the covalency and ionicity of pyrochlores show that titanates have a more covalent character than 
the highly ionic zirconates, which are more resistant to amorphization. This salient result underlines the fact that the resistance to amorphization is strongly related to the competition between short (covalent) and long (ionic) interactions.

\section{Acknowledgments}

This work was partially supported by the Groupement National de Recherche (GNR) MATINEX.

\section{References}

[1] R.C. Ewing, W.J. Weber, J. Lian, J. Appl. Phys. 95, 5949 (2004).

[2] M.A. Subramanian, G. Aravamudan, G.V.S. Rao, Prog. Solid State Chem. 15, 55 (1983).

[3] G. Sattonnay, M. Lahrichi, M. Herbst-Ghysel, F. Garrido, L. Thomé, J. Appl. Phys. 101, 103516 (2007).

[4] S. Moll, L. Thomé, L. Vincent, F. Garrido, G. Sattonnay, T. Thomé, J. Jagielski, J.M. Costantini, J. Appl. Phys. 105, 023512 (2009).

[5] G. Sattonnay, L. Thomé, J. Nucl. Mater. 348, 223 (2006).

[6] S. Moll, L. Thomé, G. Sattonnay, A. Debelle, F. Garrido, L. Vincent, J. Jagielski, J. Appl. Phys. 106, 073509 (2009).

[7] S.X. Wang, B.D. Begg, L.M. Wang, R.C. Ewing, W.J. Weber, K.V.G. Kutty, J. Mater. Res. 14, 4470 (1999).

[8] S.X. Wang, L.M. Wang, R.C. Ewing, G.S. Was, G.R. Lumpkin, Nucl. Instrum. Methods Phys. Res. B 148, 704 (1999).

[9] J. Lian, L.M. Wang, S.X. Wang, J. Chen, L.A. Boatner, R.C. Ewing, Phys. Rev. Lett. 87, 145901 (2001).

[10] B.D. Begg, N.J. Hess, D.E. McCready, S. Thevuthasan, W.J. Weber, J. Nucl. Mater. 289, 188 (2001).

[11] J. Lian, J. Chen, L.M. Wang, R.C. Ewing, J.M. Farmer, L.A. Boatner, K.B. Helean, Phys. Rev. B 68, 134107 (2003).

[12] J. Lian, L. Wang, J. Chen, K. Sun, R.C. Ewing, J.M. Farmer, L.A. Boatner, Acta Mater. 51, 1493 (2003).

[13] K.E. Sickafus, L. Minervini, R.W. Grimes, J.A. Valdez, M. Ishimaru, F. Li, K.J. McClellan, T. Hartmann, Science 289, 748 (2000).

[14] K.E. Sickafus, R.W. Grimes, J.A. Valdez, A. Cleave, M. Tang, M. Ishimaru, S.M. Corish, C.R. Stanek, B.P. Uberuaga, Nature Mater. 6, 217 (2007).
[15] M.K. Patel, V. Vijayakumar, S. Kailas, D.K. Avasthi, J.C. Pivin, A.K. Tyagi, J. Nucl. Mater. 380, 93 (2008).

[16] G. Sattonnay, S. Moll, M. Herbst-Ghysel, L. Thomé, F. Garrido, J.-M. Costantini, C. Trautmann, Nucl Instrum. Methods Phys. Res. B 266, 3043 (2008).

[17] M. Lang, J. Lian, J. Zhang, F. Zhang, W.J. Weber, C. Trautmann, R.C. Ewing, Phys. Rev. B 79, 224105 (2009).

[18] M. Lang, F.X. Zhang, R.C. Ewing, J. Lian, C. Trautmann, Z. Wang, J. Mater. Res. 24, 1322 (2009).

[19] G. Sattonnay, S. Moll, L. Thomé, C. Decorse, C. Legros, P. Simon, J. Jagielski, I. Jozwik, I. Monnet, J. Appl. Phys. 108, 103512 (2010).

[20] S. Moll, G. Sattonnay, L. Thomé, J. Jagielski, C. Decorse, P. Simon, I. Monnet, W.J. Weber, Phys. Rev. B 84, 064115 (2011).

[21] J. Zhang, M. Lang, R.C. Ewing, R. Devanathan, W.J. Weber, M. Toulemonde, J. Mater. Res. 25, 1344 (2010).

[22] G. Sattonnay, C. Grygiel, I. Monnet, C. Legros, M. Herbst-Ghysel, L. Thomé, Acta Mater. 60, 22 (2012).

[23] K. Trachenko, M. Pruneda, E. Artacho, M.T. Dove, Phys. Rev. B 70, 134112 (2004).

[24] A. Hallil, R. Tétot, F. Berthier, I. Braems, J. Creuze, Phys. Rev. B 73, 165406 (2006).

[25] R. Tétot, A. Hallil, J. Creuze, I. Braems, EPL 83, 4000 (2008).

[26] J.F. Ziegler, J.P. Biersack, U. Littmark, The Stopping and Range of Ions in Solids, Vol. 1, Ed. J.F. Ziegler, Pergamon, New York 1985.

[27] J.F. Gibbons, Proc. IEEE 60, 1062 (1972).

[28] H.Y. Xiao, W.J. Weber, J. Phys. Condens. Mater. 23, 035501 (2011).

[29] A. Hallil, E. Amzallag, S. Landron, R. Tétot, Surf. Sci. 605, 738 (2011).

[30] L. Minervini, R.W. Grimes, J. Am. Ceram. Soc. 83, 1873 (2000).

[31] A.K. Rappé, W.A. III Goddard, J. Phys. Chem. 95, 3358 (1991)

[32] J. Goniakowski, C. Noguera, Surf. Sci. 319, 81 (1994).

[33] F. Cleri, V. Rozato, Phys. Rev. B 48, 22 (1993).

[34] R. Tétot, personal communication.

[35] H.M. Naguib, R.W. Kelly, Radiat. Eff. 25, 1 (1975). 